University of Wollongong

Research Online

Faculty of Law, Humanities and the Arts Papers (Archive)

Faculty of Arts, Social Sciences \& Humanities

$1-1-2016$

Introducing a Special Issue on Rescuing Taste from the Nation: Oceans, Borders, and Culinary Flows

Cecilia Y. Leong-Salobir

University of Wollongong, cecilias@uow.edu.au

Krishnendu Ray

New York University

Jaclyn Rohel

New York University

Follow this and additional works at: https://ro.uow.edu.au/lhapapers

Part of the Arts and Humanities Commons, and the Law Commons

Research Online is the open access institutional repository for the University of Wollongong. For further information contact the UOW Library: research-pubs@uow.edu.au 


\title{
Introducing a Special Issue on Rescuing Taste from the Nation: Oceans, Borders, and Culinary Flows
}

\author{
Abstract \\ This paper introduces a special issue on "Rescuing Taste from the Nation: Oceans, Borders, and Culinary \\ Flows." It examines culinary linkages and sensory geographies across national boundaries, and highlights \\ alternative spatial configurations of taste. From the politics of tea to the transnational pathways of turtle \\ soup, papers attend to culinary cultures, systems of preparation, and forms of knowledge that escape or \\ challenge a strictly national circumscription.

\section{Disciplines} \\ Arts and Humanities | Law

\section{Publication Details} \\ Leong-Salobir, C., Ray, K. \& Rohel, J. (2016). Introducing a Special Issue on Rescuing Taste from the \\ Nation: Oceans, Borders, and Culinary Flows. Gastronomica: the journal of food and culture, 16 (1), 9-15.
}




\section{Introducing a Special Issue on Rescuing Taste from the Nation: Oceans, Borders, and Culinary Flows}

Abstract: This paper introduces a special issue on "Rescuing Taste from the Nation: Oceans, Borders, and Culinary Flows." It examines culinary linkages and sensory geographies across national boundaries, and highlights alternative spatial configurations of taste. From the politics of tea to the transnational pathways of turtle soup, papers attend to

the point of Departure for "Rescuing Taste from the Nation: Oceans, Borders, and Culinary Flows" is shared tastes across national boundaries. This special issue seeks to widen the scope of analysis by shifting the perspective from national cuisines, the dominant locus of empirical and theoretical concerns around food, to inter-Asian connections and culinary convergences. Our immediate instigation to rethink taste was the historian Prasenjit Duara's Rescuing History from the Nation: Questioning Narratives of Modern China (1997), where he argues for a reimagination of the nation-form by challenging the linear model of history that posits one path from tradition to modernity. Duara's critique is primarily about a universal, developmentalist trajectory on which various nations are imagined to be. In the process he poses questions about both the spatial imaginary of these national containers and the time-space of cultural formations such as modernity.

\section{Far and Near}

Human beings probably never imagined their social world on a planetary scale until circumnavigation (Chaplin 2012). Nevertheless, there were numerous transregional and transoceanic ties that were variously mapped, leaving a rich archive of practical human activity such as travel, trade, and pilgrimage, often bristling with maps and stories, real and imagined (Subrahmanyam 2011; Alpers 2014). We have a rich body of evidence in numerous maps connecting activities of trade and navigation. ${ }^{1}$ Ibn Battuta's fourteenth-century record of culinary cultures, systems of preparation, and forms of knowledge that escape or challenge a strictly national circumscription.

Keywords: taste, nation, transnational, inter-Asia

extensive travels shows early possibilities of literate Muslims imagining much of the Eastern Hemisphere as a unified social space (Dunn 2012). Recent work on transnationalism, globalization, and transborder connections is expanding Fernand Braudel's (1996 [1949]) view on the Mediterranean in the sixteenth century and Jacques Godechot's (1947, 1965) conception of the Atlantic in the late eighteenth century as connective rather than obstructive spaces. These reimaginings are forcing us to rethink the relationship between locations and the scope of culture making (Hunt 2014).

Long before European hegemony, Asia was a well-connected place, tied together by commercial exchanges and by religious, ethnic, and regional collaboration and conflict. Buddhism, Hinduism, and Islam spread along the very routes through which travelers, scholars, sugar, rice, tea, spices, incense, and silk circulated along the vast expanse of land and water. Material culture and conceptual schemas bridged and buffeted geographic differences. From archaeological and ethnobotanical remains of pottery, shells, coins, bone, and burnt cereal it is possible to guess that the northern rim of the Indian Ocean was already intensively connected via coasting by 5000 BCE. Linguists have shown us how an Austronesian-speaking people originating from present-day Taiwan dispersed through Hawaii, Indonesia, and Polynesia to Madagascar by a process of oceanic nomadism from $3000 \mathrm{BCE}$ into the first century $\mathrm{CE}$ with their canoes and tropical food crops (Alpers 2014). Even conflict is a form of contact (Sen 2010). Excessive attention to the world made after nation-states has muted the weight of such evidence. 


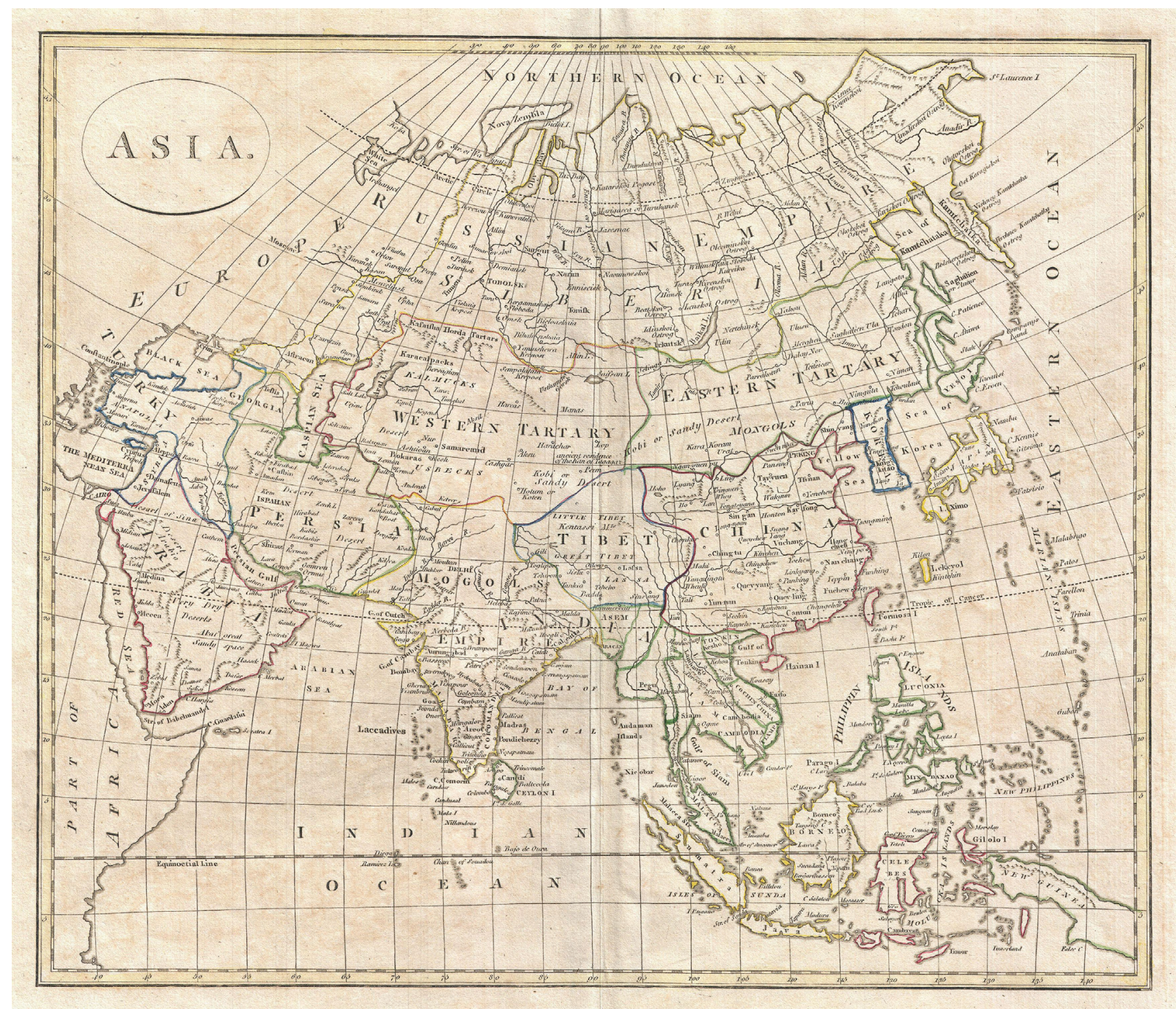

FIGURE 1: This late eighteenth-century map highlights Asia at a key moment of transition, showing topographical details, the connective spaces of major trade ports, and negotiated political and imperial terrains preceding the nation-state. It was first published in Clement Cruttwell's Atlas to Cruttwell's Gazetteer (1799).

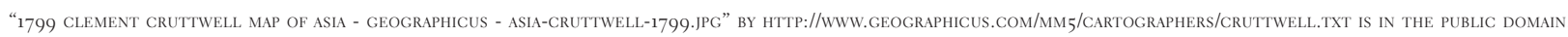

Beyond and beneath those nations, new circulations of things, people, and ideas are reinvigorating material culture and conceptions in the new Asian century. In Duara's (2015) more recent work, The Crisis of Global Modernity, and in the Epilogue in this special issue we find him digging deeper into Asian transcendental prescriptions to suggest alternative forms of sustainable futures. Similarly, to find ways out of the current environmental and international crises, the Taiwanese scholar Kuan-Hsing Chen (2010) and his colleagues (through the journal Inter-Asia Cultural Studies: Movements) recommend that we develop "Asia as Method" as a necessary route to decolonization and the reorientation of cultural studies from its Occidental self-conception. This special issue of Gastronomica brings together the work of scholars who show how such a reorientation of food studies may be undertaken by engaging fully with interAsian connections. In mining the recently robust historiography of the Indian Ocean, and inter-Asian transnationalism more broadly, numerous authors in this volume denaturalize the nation-state as the only legitimate domain of thinking about taste.

\section{High and Low}

Here we also seek to recover literal taste and corporeal sensory experience as a means of grasping cultural worlds and 
identities. We take as a starting point the claim that taste not only exists on the tongue but is a dynamic social process that encompasses production, consumption, and reproduction (Mann et al. 2011). Palatal taste and habits, especially bad habits, can be fruitfully interrogated as an embodied archive of long-term, pre- and post-Eurocentric globalization, especially where durable documentation is rare. To be able to do that we have to unthink modern Western formulations that have trivialized literal taste.

Western philosophers have long denied aesthetic legitimacy to taste on the tongue while theorizing about taste in general (Korsmeyer 1999; Dickie 1996). In their cultural history of Italian cuisine, Alberto Capatti and Massimo Montanari (2003) note how pizza and pasta have become the most recognizable signs of Italy the further one goes from it. They cite Prezzolini's question in 1954, "What is the glory of Dante compared to spaghetti?" (xx). Instead of insisting on the distinctions between palatal taste and taste in literature, they underline the point of contact between mundane practice and high art, where, "In fact, without realizing it, when we eat spaghetti we also ingest something of Dante" (xx). Capatti and Montanari flatten the aesthetic hierarchy set in place in early modern Europe. Aesthetics was born in European philosophy as a discursive field in the eighteenth century, when it was argued that literal taste is unconscious, subjective, and too intimate to allow rational elaboration. That consensus is disintegrating today.

The sharpest retort to old-fashioned theories of aesthetics had already been preemptively delivered by the seventeenthcentury nun and Hispanic Baroque scholar Sor Juana Iñes de la Cruz (2009: 75), who in responding to the chastisement of a powerful bishop noted, "If Aristotle had cooked, he would have written a great deal more." Here she was articulating a subtle theory of knowledge while making room for the caregiver's ways of knowing the world in the kitchen, the parlor, and the nursery, and writing about it. Emerging from those apparently narrow confines, such knowledge can illuminate the larger world if we are willing to learn from the work of cooks and caregivers. The conjoined arts of cooking and thinking can be brought together, and palatal taste can be recovered as a legitimate site of biosocial engagement.

Because literal taste is produced by the configuration of bodies, places, and objects (Hennion 2007), it allows us a window into the biological, the geographical, and the social that corrects excessive consideration of the nature/culture divide rather than the connections. In this special issue we are responsive to that intersection by taking apparently trivial, sometimes psychotropic comestibles-beer, tea, roasted chickpea powder (sattu), turtle soup-and dynamic processes of culinary craft and caregiving to show the importance of transnational and transoceanic connections, the depth of globalization, the folly of presuming bounded national tastes, and the separation of the biological from the sociological, the historical and the geographical.

In mapping tastes across time and place in Asia, colonial regimes produced hybrid cuisines, highlighting the flexibility of alimentary substances and the work of cooks, caregivers, and masters. For instance, centuries of intermarriage between Dutch and Javanese created distinctively hybrid foodways in the Netherland Indies (Protschky 2008). Dutch colonists were keenly familiar with Indies culture, but they used taste to distinguish themselves from the natives to demonstrate that they were capable colonists. Fermented soya bean (tempe), for instance, was not seen as something suitable for the Dutch kitchen nor for Dutch mouths (Protschky 2008). By contrast, the Portuguese colonial elite and even French colonizers helped forge culinary connections within their respective colonies (Zubaida 2009; Burton 2000). In Portuguese settlements from Madras and Bengal to Thailand, Burma, Malacca, and Ceylon, fish often replaced meat in traditional Iberian stews and braises, and Asian ingredients such as coconut milk were introduced to baked goods (Boileau 2010). Luso-Asian families in Goa consumed an array of dishes for the evening meal, showcasing the Portuguese adoption of indigenous culinary elements: soup and bread, feni (cashew or coconut spirit), cocktails or sangria, cashews, codfish balls or shrimp rissoles; followed by grilled tiger prawns, pork flavored with balchāon (fermented prawn dish), prawn and kingfish curries, roasted pomfret stuffed with chilli paste, Goan sausages fried with potatoes and onions, European breads and Indian chapatis, rice, pilaf, vegetable dishes, and a selection of pickles and condiments; and then alcohol, pudding, flan, or bebinca (Goan cake made with coconut and jaggery) and fresh fruit (Boileau 2010). Unencumbered by the dictates of classical cuisine, the French experimented with local ingredients in the Indian Ocean region. Lobster was cooked with pineapple in Mauritius, and curries and rougails (fresh chutneys) commonly accompanied imported truffles, goose, and Gruyère cheese on the dinner tables of plantation owners (Burton 2000). Taste, in the colonial context, was in turn ambiguous and rigid, dictated by both local conditions and colonial strictures.

Curries, mulligatawny, kedgeree, country captain, pishpash, and sago pudding appeared daily on the British colonial table in India, Malaysia, and Singapore in the nineteenth and twentieth centuries. The colonial hybrid cuisine evolved over time and was a combination of culinary practices derived from European and Asian foodways. The meals were procured and prepared entirely by local domestic servants, 
with the cooks playing no small part in deciding what ingredients were inappropriate for the rulers, omitting many "lowly" food items that were consumed by the local inhabitants. At the same time they also decided what dishes and ingredients were fitting for the rulers' diet. In the negotiation process of what was permissible and what was not-between the memsahib/sahib and the cook in the days of the East India Company - the cue was to serve the British foods similar to those consumed by the Mughal rulers. As such, the British inherited the high-status Mughlai pilaus and dum poked chickens (Collingham 2005).

The British colonial culinary experience was fluid; foods eaten by colonizers in each colony made geographical leaps to other colonies. Thus, a pan-colonial cuisine emerged, with subtle regional differences. Historian Thomas Metcalf's (2007) premise that tools or instruments of empire radiated outward from the Raj in India to other parts of Asia could apply to culinary practices. Indeed, curry was a dish that found a place on colonial tables across European empires. The British appropriated curry from India during the colonial era, but it evolved and mutated both temporally and geographically. Its popularity peaked in the days of the East India Company when its employees embraced all things Indian. Even in its colonial days, curry spread from presidency to presidency in the subcontinent and across the colonies in the British Empire and beyond. It stood out as the single most important dish that defined the culinary history of British imperialism, becoming the mainstay of colonial cuisine (Leong-Salobir 2011). British colonials relished debating which household produced the tastiest curries, taking pride in the curry-making skills of the cooks.

Such instances of colonial hybrid cuisines highlight the expedient and pragmatic ways in which European colonizers negotiated with the colonized Asians. Local domestic servants were key brokers of taste; they helped forge hybrid cuisines by purchasing ingredients, cooking meals, and serving the colonizers. Some of their colonial hybrid dishes and meals survived well beyond colonialism. These have been kept alive in many postcolonial communities where elites have acquired a taste for various components of the constructed colonial cuisines. In the years after independence, for example, Asian elites began to frequent refurbished colonial-style grand hotels-Raffles in Singapore, Eastern and Oriental in Penang, Grand Hotel in Calcutta, Métropole in Hanoi and the Continental, Majestic and Grand in Ho Chi Minh City. The appeal of the grand hotels lay in the reliving of a colonial past, through period décor, entertainment, and British colonial dishes such as curries, spotted dick, mulligatawny soup, chicken chop, and sago pudding (Peleggi 2005).
Many of these colonial preparations take shape at the intersection of real and imagined borders, such as "Indian," "Malaysian," or even "English." Their emergence from nonlinear genealogies demonstrates the necessity of recuperating taste and sensual memory as forms of history that have long been denied by European models and maps (Cho 2010). Colonial dishes show us that if we take taste and sensual memory seriously, then the geography can shift. Geography is not destiny, but it has been underaccounted in the anthropocentric antimaterialism of the traditional humanities, in a justified but overcompensating attempt to discount the ecological determinism of what preceded (cf. Appadurai 2010). In spite of some errors and exaggerations, the geographer, environmental historian, and biologist Jared Diamond much more successfully posited a productive relationship between local places and continental spaces in Guns, Germs, and Steel (1997), while humanistic approaches could not connect the dots.

Let us take the instance of fermented fish sauce, which is a popular condiment for rice bowls across the Mekong Valley, where fish stocks fluctuate with monsoon seasonality, and where rice cultivation and salt production predominate (Ruddle and Ishige 2010). Salting and fermenting fish releases the amino acid glutamate, leading to a transformation of taste (savory, meaty, spicy, umami); it also produces a preserved condiment that people throughout the region and across national borders eat as a flavor enhancer out of season (Mouritsen and Styrbæk 2014; Ishige 1993). Variations in boiled rice and fish sauce demarcate ethnic and regional differences along the Mekong River, though in border countries such as Thailand, Vietnam, Cambodia, and Burma these ingredients are nonetheless incorporated into an "emerging "national' culture" (Lefferts 2005: 248). There is an ideological imperative to fix gustemic identity at borders (see, for instance, Guy 2007; Mookherjee 2008; Walker 2013), but such projects of nation making are political and cultural works in progress revealed by narratives of taste and tradition coexisting among many other practices and possibilities, some palpable, others unpalatable.

The fragmentary histories of the nation-and the collective tastes above, below, and between them-become especially obvious when we turn to volatile border regions. The Indo-Pak border (implemented during the 1947 Partition amid religious and ethnic conflict and mass migrations) crosses the Indo-Gangentic Plain and traverses fertile fields of basmati rice. Anthropologist Denis Vidal's (2005) work on agro-politics in Indian border regions illuminates the global dispute over seeds, heritage, and biopiracy that erupted when an American company secured a patent over basmati rice and tried to commercialize the product in the United States. 
The company's attempts were shut down by cooperative efforts between India and Pakistan to regain a monopoly within a few years. This alliance penetrated a shared gustemic identity that had not been formalized or articulated into tangible heritage. The incident precipitated "a form of pan-South Asian [culinary] patriotism" (51). The connected geography of basmati rice has since splintered the two nations in the race to secure geographical indication status and mark out a territory that Vidal aptly describes as "Basmatisthan" (61). But, it must be underlined, this splintering occurs against a backdrop of shared agro-ecological conditions, tastes, embodied knowledges, intergenerational transmissions, and sensual memories.

The above cases highlight some of the ways in which transnational narratives of taste and hybridity are configured. Numerous other examples abound, from the global flow of kedgeree/kitchri/kitchari/kushari throughout kitchens in South Asia, the Middle East, North Africa, and Britain (Zubaida 2009) to the widespread chewing of betel nuts across the Indian Ocean region. Chronicles of taste can be multiple, forged across uneven terrains of power. They can rupture borders, revealing conflicting tales and tastes that can be obfuscated by linear histories and normative models of the nation and of good taste. And they can illustrate a transnational politics of discernment, an important reminder of Michel de Certeau's (1984: 129) astute observation that "What the map cuts up, the story cuts across" (see also Ghosh 2011: 51).

\section{Connections, Convergences, Comparisons}

This special issue examines the culinary linkages and sensory geographies - past and present-that exceed national containers. In so doing, the authors build on interventions that trace transnational foodways and historical connections. The recent volume Rice and Beans: A Unique Dish in a Hundred Places, by anthropologists Richard Wilk and Livia Barbosa (2012), brilliantly captures how "the distribution of rice and beans maps out the Atlantic world, the Caribbean basin with extension and expansion into the mainlands to the north, west, and south" (5). While this project interrogates a common dish at different scales of a "culture complex" (5) attending to similarities and differences among individuals, classes, ethnicities, and nations within the Atlantic regionour ambition is to reassess the ways in which collective taste is sutured to the nation by taking inter-Asia (SSRC 2013) as our field of analysis. Our approach also responds to a call to problematize taste, culinary identity, and the in-between spaces of borders (Pérez and Abarca 2007) and extends it. We draw attention to the edges of nations and continents to highlight the fragility of nationalized taste, showing how cosmopolitanisms and localisms of taste are forged in the interstitial spaces between territories and across inter-Asian connections.

May-bo Ching and Ashutosh Kumar both examine how transformations of taste have unfolded over and across bodies of water through historical studies of the global reaches of the British Empire. Ching's analysis of the sea turtle spans three continents and as many centuries, but focuses on the transition of turtle soup from basic sustenance for transatlantic seamen in the Caribbean to status marker in British trading posts in nineteenth-century Canton. By unpacking recipes for turtle soup after the English fashion, Ching repositions taste and charts a new geography that undermines what she calls "the East-West dichotomy in culinary cultures." Kumar picks up the thread on European colonial ambitions by looking at the politics of provisioning on ships of indentured workers from northern India to the Caribbean and the South Pacific and Indian Oceans. Through a political economy of food and careful analysis of archived emigration records, he shows how the ships configured a new dietary space where officials accommodated laborers' tastes and enabled new kinship bonds through changes in eating practices and the collapse of caste boundaries. Both authors importantly situate taste within a network of global flows and colonial power relations.

Articles by Jean Duruz and by Zafer Yenal and Michael Kubiena examine discourses of taste and cosmopolitanism through analyses of cooking in private and public domains from a more contemporary perspective. Duruz takes us on a journey through the kitchens of Eurasian and Peranakan communities in port cities across the Indian Ocean. By tracing family recipes and the "food of love," she shows how a sensory geography that attends to discourses of hybridity and mixed dishes challenges dominant ways of seeing place; communities of caring and sensual memories disclose new maps of places and the connections between them. Yenal and Kubiena move us to an urban crossroad, where East meets West. Their focus on the shifting culinary landscape of Istanbul over the last few decades highlights contested domains of legitimate taste. While authenticity once connoted a historical or regional cuisine in Turkey, they show how the global professionalization of chefs and the liberalization of the Turkish economy have produced new public cultures of consumption in Istanbul that privilege localism and give new meanings to authentic taste. They argue that this phenomenon represents a transition to a global, cosmopolitan culinary order that escapes a national food culture.

Finally, contributions by Jeffrey M. Pilcher and Lawrence Zhang productively recuperate the idea of the nation. By analyzing the nationalization of drink and the politics of 
modernity through a transnational lens, they each show how taste can be negotiated in the spaces and connections between nations. Focusing on multiple instantiations of imperial relationships, Pilcher charts the flow of beer from Europe to Asia through circulations and comparisons across China, Japan, and India, showing how the very cosmopolitanism of beer in fact supported efforts to consolidate nationhood in these three contexts. Zhang shifts the focus to another beverage, documenting how gongfucha tea recently transformed from a regional practice in Chaozhou to a popular Chinese custom by way of Taiwan and Japan. He shows how the nationalization of this taste rested upon diasporic flows in Taiwan and cultural borrowing from Japanese tea arts (senchadō), thereby dismantling common narratives that position China as a national whole from which tea radiates outward to adjacent regions in East Asia. Both articles illustrate how migrants, merchants, and movements within transnational networks and fields of power shape taste across an interconnected Asia.

Beginning with Duara's (1997, 2015) call to move beyond the model of linear history, this special issue motivates a study of gustatory practice and imagination in and across Asia, charting "connections, convergences, and comparisons" (SSRC 2013) of the nation-form and its multiple Others. Each of the contributions in this collection provides a new window into theorizing globalization by critically engaging pathways of cultural identity that exceed the nation, both spatially and temporally. Collectively, papers in this issue deploy a broad spatial imagination to show how globalization works through a range of sites and geographies, from the intimate perceptions of the body to microcosmic sites of dwelling places, to borderlands, vast territories, oceans, and circulations between them. In doing so, they disrupt the selfsame consciousness of the nation-form to recover new geographies of tastes and gustemic communities. @

\section{Acknowledgments}

This paper and the accompanying special issue developed out of a workshop at a conference on Inter-Asian Connections IV in Istanbul in October 2013, co-sponsored by the Social Science Research Council (SSRC) and Koç University, Göttingen University, Yale University, the Hong Kong Institute for the Humanities and Social Sciences (HKIHSS) at the University of Hong Kong, and the National University of Singapore (NUS). We are grateful to the conference organizers, especially Holly Danzien, and to all of the workshop participants for their contributions to a robust and thought-provoking session. Jean Duruz and Sierra Clark each offered very helpful comments on the workshop concept note, an early version of this piece. We also extend our thanks to Melissa Caldwell, Carla Takaki Richardson, and the many anonymous reviewers at Gastronomica for encouraging the further development of this dialogue, and to all at the journal who made this special issue possible. A few of the ideas presented here were first articulated in Food Culture in Colonial Asia: A Taste of Empire (Leong-Salobir 2011) and in "Indian Ocean Cuisine? Outline of an Argument on the Limits of National Cultures" (Ray 2013).

NOTE

1. Examples include the anonymous Periplus of the Erythraen Sea (ca. 50 CE), the Egyptian Book of Curiosities (ca. 1020-1050 CE), the Ming cartographer's Amalgamated Map of the Great Ming Empire (ca. 1389 CE), and the Omani navigator Ahmad ibn Majid's Book of Useful Information on the Principles and Rules of Navigation (ca. $1490 \mathrm{CE}$ ) (Alpers 2014; Lunde 2005).

\section{REFERENCES}

Alpers, Edward A. 2014. The Indian Ocean in World History. New York: Oxford University Press.

Appadurai, Arjun. 2010. "How Histories Make Geographies: Circulation and Context in a Global Perspective." Transcultural Studies 1(1): 4-13

Boileau, Janet P. 2010. "A Culinary History of the Portuguese Eurasians: The Origins of Luso-Asian Cuisine in the Sixteenth and Seventeenth Centuries." PhD thesis, University of Adelaide.

Braudel, Fernand. 1996 [1949]. The Mediterranean and the Mediterranean World in the Age of Philip II. 2 vols. Berkeley: University of California Press.

Burton, David. 2000. French Colonial Cookery: A Cook's Tour of the French-Speaking World. London: Faber and Faber.

Capatti, Alberto and Massimo Montanari. 2003. Italian Cuisine: A Cultural History. New York: Columbia University Press.

Chaplin, Joyce E. 2012. Round around the Earth: Circumnavigation from Magellan to Orbit. New York: Simon \& Schuster.

Chen, Kuan-Hsing. 2010. Asia as Method: Towards Deimperialization. Durham, NC: Duke University Press.

Cho, Lily. 2010. Eating Chinese: Culture on the Menu in Small Town Canada. Toronto: University of Toronto Press.

Collingham, Lizzie. 2005. Curry: A Biography. London: Chatto \& Windus.

de Certeau, Michel. 1984. The Practice of Everyday Life. Translated by Steven Rendall. Berkeley: University of California Press.

Diamond, Jared M. 1997. Guns, Germs and Steel: The Fates of Human Societies. New York: Norton.

Dickie, George. 1996. The Centuries of Taste. Oxford: Oxford University Press.

Duara, Prasenjit. 1997. Rescuing History from the Nation: Questioning Narratives of Modern China. Chicago: University of Chicago Press.

- 2015. The Crisis of Global Modernity: Asian Traditions and a Sustainable Future. Cambridge: Cambridge University Press.

Dunn, Ross E. 2012. The Adventures of Ibn Battuta. Berkeley: University of California Press.

Ghosh, Sahana. 2011. "Cross-border Activities in Everyday Life: The Bengal Borderland." Contemporary South Asia 19(1): 49-60.

Godechot, Jacques. 1947. Histoire de l'Atlantique. Paris: Bordas. 
1965. France and the Atlantic Revolution of the Eighteenth Century, 1770-1799. New York: Free Press.

Guy, Kolleen. 2007. When Champagne Became French: Wine and the Making of a National Identity. Baltimore: Johns Hopkins University Press.

Hennion, Antoine. 2007. "Those Things That Hold Us Together: Taste and Sociology." Cultural Sociology 1(1): 97-114.

Hunt, Lynn. 2014. Writing History in the Global Era. New York: W. W. Norton.

Iñes de la Cruz, Sor Juana. 2009. La Respuesta (The Answer). Translated and edited by E. Arenal and A. Powell. New York: Feminist Press.

Ishige, Naomichi. 1993. "Cultural Aspects of Fermented Fish Products in Asia." In Fish Fermentation Technology, ed. CherlHo Lee, Keith H. Steinkraus, and P. J. Alan Reilly, 13-32. Tokyo: United Nations University Press.

Korsmeyer, Carolyn. 1999. Making Sense of Taste: Food and Philosophy. Ithaca, NY: Cornell University Press.

Lefferts, Leedom. 2005. "Sticky Rice, Fermented Fish, and the Course of a Kingdom: The Politics of Food in Northeast Thailand." Asian Studies Review 29(3): 247-58.

Leong-Salobir, Cecilia. 2011. Food Culture in Colonial Asia: A Taste of Empire. London: Routledge.

Lunde, Paul. 2005. "The Navigator Ahmad Ibn Majid." Saudi Aramco (July/August): 45-48.

Mann, Anna M., Annemarie M. Mol, Priya Satalkar, Amalinda Savirani, Nasima Selim, Malini Sur, and Emily Yates-Doerr. 2011. "Mixing Methods, Tasting Fingers: Notes on an Ethnographic Experiment." HAU: Journal of Ethnographic Theory 1(1): 221-43.

Metcalf, Thomas R. 2007. Imperial Connections: India in the Indian Ocean Arena, 1860-1920. Berkeley: University of California Press.

Mookherjee, Nayanika. 2008. "Culinary Boundaries and the Making of Place in Bangladesh." South Asia: Journal of South Asian Studies 31(1): 56-85.

Mouritsen, Ole G. and Klavs Styrbæk. 2014. Umami: Unlocking the Secrets of the Fifth Taste. Translated by Mariela Johansen. New York: Columbia University Press.

Peleggi, Maurizio. 2005. "Consuming Colonial Nostalgia: The Monumentalisation of Historic Hotels in Urban South-East Asia." Asia Pacific Viewpoint 46(3): 255-65.
Pérez, Ramona Lee and Meredith Abarca. 2007. "Cocinas Públicas: Food and Border Consciousness in Greater Mexico." Food and Foodways 15(3-4): 137-51.

Protschky, Susie. 2008. "The Colonial Table: Food, Culture and Dutch Identity in Colonial Indonesia." Australian Journal of Politics and History 54(3): 346-57.

Ray, Krishnendu. 2013. "Indian Ocean Cuisine? Outline of an Argument on the Limits of National Cultures." In "Western Australia in the Indian Ocean World," ed. Ruth Morgan, Cecilia Leong-Salobir, and Jeremy Martens, special issue. Studies in Western Australian History 28: 119-31.

Ruddle, Kenneth and Naomichi Ishige. 2010. "On the Origins, Diffusion and Cultural Context of Fermented Fish Products in Southeast Asia." In Globalization, Food and Social Identities in the Asia Pacific Region, ed. James Farrer. Tokyo: Sophia University Institute of Comparative Culture. Available at http://icc. fla.sophia.ac.jp/global\%2ofood\%2opapers/pdf/1_2_RUDDLE_ ISHIGE.pdf (accessed December 16, 2014).

Sen, Tansen. 2010. "The Intricacies of Premodern Asian Connections." Journal of Asian Studies 69(4): 991-99.

SSRC (Social Science Research Council). 2013. International Conference on Inter-Asian Connections IV: Istanbul. Available at http://webarchive.ssrc.org/pdfs/IACIV_Complete\%2oProgram. pdf (accessed December 23, 2014).

Subrahmanyam, Sanjay. 2011. Explorations in Connected History: From the Tagus to the Ganges. Oxford: Oxford University Press.

Vidal, Denis. 2005. "In Search of 'Basmatisthan': Agro-Nationalism and Globalization.” In Globalizing India: Perspectives from Below, ed. Jackie Assayag and C.J. Fuller, 47-64. London: Anthem Press.

Walker, Margath A. 2013. "Border Food and Food on the Border: Meaning and Practice in Mexican Haute Cuisine." Social 6 . Cultural Geography 14(6): 649-67.

Wilk, Richard and Livia Barbosa. 2012. "A Unique Dish in a Hundred Places." In Rice and Beans: A Unique Dish in a Hundred Places, ed. Richard Wilk and Livia Barbosa, 1-17. London: Berg.

Zubaida, Sami. 2009. "The Idea of 'Indian Food': Between the Colonial and the Global." Food and History 7(1): 191-209. 